\title{
Optimization of growth media components for polyhydroxyalkanoate (PHA) production from organic acids by Ralstonia eutropha.
}

\begin{abstract}
We employed systematic mixture analysis to determine optimal levels of acetate, propionate, and butyrate for cell growth and polyhydroxyalkanoate (PHA) production by Ralstonia eutropha H16. Butyrate was the preferred acid for robust cell growth and high PHA production. The 3-hydroxyvalerate content in the resulting PHA depended on the proportion of propionate initially present in the growth medium. The proportion of acetate dramatically affected the final $\mathrm{pH}$ of the growth medium. A model was constructed using our data that predicts the effects of these acids, individually and in combination, on cell dry weight (CDW), PHA content (\%CDW), PHA production, $3 \mathrm{HV}$ in the polymer, and final culture $\mathrm{pH}$. Cell growth and PHA production improved approximately 1.5 -fold over initial conditions when the proportion of butyrate was increased. Optimization of the phosphate buffer content in medium containing higher amounts of butyrate improved cell growth and PHA production more than 4-fold. The validated organic acid mixture analysis model can be used to optimize R. eutropha culture conditions, in order to meet targets for PHA production and/or polymer $\mathrm{HV}$ content. By modifying the growth medium made from treated industrial waste, such as palm oil mill effluent, more PHA can be produced.
\end{abstract}

Keyword: Polyhydroxyalkanoate; Ralstonia eutropha; Organic acid; Mixture model. 